\title{
Excess mortality from avoidable and non-avoidable causes in men of low socioeconomic status: a prospective study in Korea
}

\author{
Yun-Mi Song, Jai Jun Byeon
}

\begin{abstract}
Study objective-The objective of this study was to evaluate the magnitude and contributory factors of socioeconomic differentials in mortality in a cohort of Korean male civil servants.

Design-A prospective observational study of male civil servants followed up for five years after baseline measurement.

Setting-All civil service offices in Korea. Participants and measurements-The study was conducted on 759665 Korean male public servants aged 30-64 at baseline examination in 1992. The grade of monthly salary of these participants divided into four groups, a proxy indicator of socioeconomic status (SES), was the main predictive variable. Mortality of the participants was followed up from 1992 to 1996. The causes of deaths were categorised into four groups according to the medical amenability: avoidable, partly avoidable, non-avoidable, and external causes of death. The risk of mortality associated with SES was estimated using the Cox proportional hazard model.

Main results-Lowest SES group had significantly higher risk of mortality from most causes compared with the highest SES group in the order of external cause (relative risk (RR): 2.26), avoidable (RR: 1.65), all cause (RR: 1.59), and nonavoidable mortality (RR: 1.54 ). With the adjustment of known risk factors, significantly higher risks of mortality in lowest SES group were attenuated but persisted. Looking at the deaths from partly avoidable causes, significantly higher risks of mortality in the lowest SES group was observed from cerebrovascular disease but not from coronary heart disease.

Conclusions-Socioeconomic differentials in non-avoidable as well as avoidable mortality, persisting even under the control of risk factors, suggest that mortality is influenced not only by the quality of health care and different distribution of risk factors but also by other aspects of SES that are yet unknown.

(F Epidemiol Community Health 2000;54:166-172)
\end{abstract}

Mortality is influenced by several factors other than individual health habits and biological characteristics. Among the many factors related to mortality, socioeconomic status (SES) has been an issue of interest to the researchers in the field of public health for a long time. ${ }^{12}$
There have been many studies documenting socioeconomic differentials in mortality from all cause and specific causes like cancer and coronary heart disease in well developed countries. ${ }^{3-10}$ Judging on the grounds of equity in distribution of social resources, it is necessary to investigate the relation between SES and mortality in less developed countries where problems related to socioeconomic inequality seem to be more serious.

If the differences in mortality according to SES are observed universally, what can be the reason for these differences? Considering the correlation between medical care supply and socioeconomic condition ${ }^{11} 12$ and between health care supply and mortality, ${ }^{13}$ examining the effect of SES on the mortality from causes amenable to medical intervention might give some clues to the relation between SES and mortality. Mortality avoidable by medical intervention, proposed first by Rutstein group in $1976^{14}$ and defined as "unnecessary untimely mortality" or "mortality wholly or substantially avoidable by adequate medical care", has been used in several studies as a method for the measurement of the quality of health care. Many researchers, through the aggregate data studies, have reported on the variations of mortality from diseases avoidable by medical intervention in areas with different levels of health care resources and socioeconomic conditions. Mortality from avoidable diseases, although not completely confirmed, seemed to decrease with the growth in socioeconomic conditions and health services. ${ }^{15-17}$

The possibility that known risk factors account for socioeconomic differentials in mortality has been suggested. In many studies, persons of lower SES were more likely to be obese and reported higher rates of smoking and drinking. They were also more likely to have higher levels of blood pressure and cholesterol. ${ }^{18-25}$

The authors carried out this study to examine the magnitude and causes of the socioeconomic differentials in mortality in a population of a less developed country, Korean male civil servants.

\section{Methods}

STUDY POPULATION AND VARIABLES

Every Korean citizen is covered by the obligatory National Health Insurance System. Unfortunately, this system does not provide a full health care coverage but is under the copayment benefit structure. 
Regardless of occupation, economic status, and the area of residency, all the government employees and their family members are covered by the Korea Medical Insurance Corporation, one of the two major national health insurance agencies in Korea. The subjects in this study included all Korean male civil servants (759 $665 \mathrm{men}$ ) aged 30 to 64 in the year 1992 .

The grade of monthly salary, which was regarded as an indicator of SES directly reflecting individual income and having parallel relation with the grade of position, was the main predictive variable of this study. Information on the grade of monthly salary in 1992 was obtained from the Korea Medical Insurance Corporation by which it had been used as the basis for charging the premium for medical insurance.

Since 1980, the Korea Medical Insurance Corporation have provided biannual multiphasic health examination services to all those who were insured. Questionnaires inquiring of health habits were self administered during health examination period. Serum cholesterol concentration, blood pressure, weight, and height were measured. Venous blood was obtained in the morning after fasting overnight in accordance with the health examination regulation of the Korea Medical Insurance Corporation. All medical institutes that carried out the health examination were equipped with standardised high quality laboratories authorised by the Korea Association of Clinical Pathology and the Korea Association of Quality Control over Clinical Laboratory Examination.

The information on the various biological and behavioural factors such as blood pressure, height, weight, serum cholesterol, smoking habit, alcohol drinking habit, type of occupation, and the area of residency were obtained from the health examination data set of Korea Medical Insurance Corporation.

To examine the effect of biological and behavioural factors on the relation between SES and mortality more accurately, efforts were made to minimise the missing values in these variables. Health examination data of 643366 men $(84.7 \%$ of study subjects) were obtained from the data set of 1992, and those of 60481 men $(8.0 \%)$ were obtained from the data set of 1990 and 1994. Data on smoking and drinking habits of 633715 men $(83.4 \%)$ were obtained from the 1992 data set, and of 72498 men (9.5\%) from the 1990 and 1994 data set.

The death registry of the Korea National Office from January 1992 to December 1996 was checked thoroughly for the vital status of the studied subjects. Complete vital information on all study subjects was available as all deaths must be reported to the Korea National Statistical Office by submitting a death certificate. The accuracy of the code for the cause of death according to the death certificate was evaluated by comparing the cause of deaths having occurred between July 1995 and September 1995 with medical service utilisation data set of Korea Medical Insurance Cor- poration. We did not evaluate the accuracy of the code for deaths from external causes because any mobility from traffic accidents and suicide attempts were not covered by medical insurance service. The code for the cause of death according to the Korea National Statistical Office was 72.4 per cent accurate (412 of 569 cases were concordant). There was no significant difference in the accuracy of the causes of death among the four SES groups.

Selection of mortality avoidable by medical intervention was based on the list of "Avoidable deaths (Clear-cut, immediate use of Quality-of-Care Indexes)" and "Partly avoidable deaths (Limited use of Quality-of -Care Indexes)" proposed by the Rutstein group. ${ }^{14}$ Mortality from external causes, most of which could have been influenced by extra-medical factors, was classified as another discrete category. Deaths from transport accident, accidental injury, intentional self harm, assault, and the complications of medical and surgical care were classified into the category of mortality from external causes.

\section{STATISTICAL METHODS}

SES was classified into four levels according to the quartile distribution of the grade of monthly salary: level I corresponds to the monthly salary under 769 dollars; level II from 769 to 979 dollars; level III from 979 to 1307 dollars; and level IV over 1307 dollars. Body mass index, calculated as weight $(\mathrm{kg})$ per height squared $\left(\mathrm{m}^{2}\right)$, was used to classify the study subjects into three relative weight groups: underweight (lower than $20 \mathrm{~kg} / \mathrm{m}^{2}$ ); normal weight (20-25 kg/m²); and overweight (25 $\mathrm{kg} / \mathrm{m}^{2}$ or more). For smoking status, study subjects were classified into three groups: nonsmoker; former smoker; and current smoker. Information on the exact amount and frequency of alcohol intake was not available for some subjects whose health habit information was obtained from the 1990 dataset. Therefore, drinking habits were classified into three groups: non-drinker, occasional drinker, and frequent drinker. Area of residency was categorised as large city, medium and small city, and county according to the administrative division. Occupation was categorised into "high" group and "low" group: educational, administrative, professional, and executive occupations were regarded as "high" group occupation; whereas, manual, partly skilled, and unskilled occupations and police officers were of the "low" group occupation.

Relative risks of mortality and $95 \%$ confidence intervals were estimated by the Cox proportional hazard regression analysis using the PC/SAS statistical package. ${ }^{26}$ Age by one year, relative weight (underweight, normal, overweight), cholesterol by one $\mathrm{mg} / \mathrm{dl}$, systolic blood pressure by one $\mathrm{mm} \mathrm{Hg}$, smoking habit (non-smoker, former smoker, current smoker), drinking habit (non-drinker, occasional drinker, and frequent drinker), area of residency (large city, medium and small city, county), and the type of occupation ("high" group, "low" group) were added for multivariate analysis. 
Table 1 Mortality from avoidable causes that occurred among 759665 men aged 30-64 during the five year follow up period (1992-1996), Korea

\begin{tabular}{|c|c|c|c|c|c|}
\hline ICD 8 code & ICD 9 code & ICD 10 code & Causes of death & $\begin{array}{l}\text { Number of } \\
\text { deaths }\end{array}$ & $\begin{array}{l}\text { Type of } \\
\text { intervention }\end{array}$ \\
\hline 010-019 & $010-018$ & A15-A19 & Tuberculosis ( all forms) & 132 & Treatment \\
\hline 141 & 141 & $\mathrm{C} 02$ & Malignant neoplasms of dorsal and ventral surfaces, borders & 20 & Prevention \\
\hline $144-145$ & 144,145 & $\begin{array}{l}\mathrm{C} 04 \\
\mathrm{C} 06\end{array}$ & and tip of tongue, floor of mouth, or buccal mucosa & & Treatment \\
\hline 161 & 161 & $\mathrm{C} 32$ & Malignant neoplasms of larynx & 53 & $\begin{array}{l}\text { Prevention } \\
\text { Treatment }\end{array}$ \\
\hline 162 & 162 & C33,34 & Malignant neoplasms of trachea, bronchus, lung & 751 & Prevention \\
\hline 173 & 173 & C44 & Other malignant neoplasms of skin & 9 & Treatment \\
\hline 188 & 188 & C67 & Malignant neoplasms of bladder & 30 & Prevention \\
\hline 193 & 193 & $\mathrm{C} 73$ & Thyroid carcinoma & 11 & Prevention \\
\hline 205 & 205 & C92 & Myeloid leukaemia & 44 & Prevention \\
\hline 242 & 242 & E05 & Thyrotoxicosis with or without goitre & 4 & Treatment \\
\hline 269 & 269 & E63 & Other nutritional deficiencies & 2 & $\begin{array}{l}\text { Prevention } \\
\text { Treatment }\end{array}$ \\
\hline $280-281,284$ & $280,281,284$ & $\begin{array}{l}\text { D50-D52, } \\
\text { D60-D61 }\end{array}$ & Anaemia & 10 & $\begin{array}{l}\text { Prevention } \\
\text { Treatment }\end{array}$ \\
\hline 320 & 320 & G00 & Bacterial meningitis & 1 & Treatment \\
\hline $381 \mathrm{M}-383 \mathrm{M}$ & $381-383$ & H65-H67 & Otitis media of mastoiditis & 1 & Treatment \\
\hline 426 & $415-417$ & I26-I27 & Pulmonary heart disease & 8 & Prevention \\
\hline $480-487$ & $480-487,490$ & $\begin{array}{l}\text { J10-J18, } \\
\text { J20, J40 }\end{array}$ & $\begin{array}{l}\text { Pneumonia, influenza, } \\
\text { Bronchitis }\end{array}$ & 66 & Treatment \\
\hline 491-492 & $490-492,496$ & J41-J44, & Chronic obstructive lung disease & 53 & Prevention \\
\hline 493 & 493 & J45-J46 & Asthma & 59 & Treatment \\
\hline $515-516$ & $500-505$ & $\mathrm{~J} 60-65$ & Pneumoconiosis & 7 & Prevention \\
\hline $540-543$ & $540-543$ & K35-K38 & Appendicitis & 3 & Treatment \\
\hline $550-553$ & $550-553$ & K40-k46 & Inguinal or other hernias of abdominal cavity & 1 & Treatment \\
\hline $574-575$ & $574-575$ & K81 & Cholecystitis & 10 & Treatment \\
\hline $680-686$ & $680-686$ & L00-L08 & Infections of skin and subcutaneous tissues & 1 & Treatment \\
\hline 720 & 730 & M86 & Osteomyelitis & 2 & Treatment \\
\hline $780-799^{\star}$ & $780-799$ & R00-R99 & Symptoms and ill defined conditions & 262 & \\
\hline
\end{tabular}

^Included in this table as an index of poor quality of health care.

Cox proportional hazard regression analysis was repeated to assess the extent to which the socioeconomic differentials in mortality could be explained by other factors. Occupational group and the area of residency, which might be considered as other social factors having confounding effect on the relation between SES and mortality, were treated separately to clarify the effect of biological and behavioural risk factors in the relation between SES and mortality.

\section{Results}

During the five year follow up period, there were a total of 13330 deaths among the 759665 men. Of these, 1540 deaths (11.6\%) were attributable to avoidable causes, 2769 deaths $(20.8 \%)$ to partly avoidable causes, 2609 deaths $(19.6 \%)$ to external causes, and 6412 deaths $(48.1 \%)$ to non-avoidable causes.

Tables 1 and 2 present the detailed lists of avoidable and partly avoidable causes of deaths among the study subjects. Cancer was the most common avoidable cause of death. Hypertensive disease with vascular complications of brain was the most common partly avoidable cause of death.
Age adjusted baseline characteristics of the subjects in relation to SES are presented in table 3. There were significant associations between the biological and social characteristics and the level of SES. Men of higher SES had higher levels of serum cholesterol than those of the lower SES group. Prevalence rate of overweight was higher in men of higher SES than in men of lower SES. However, the levels of diastolic and systolic blood pressure were higher and smoking was more prevalent in the low SES group. There was no significant difference in the drinking habit among different SES groups. The proportion of men living in large cities and being engaged in high group occupations were larger in men of higher SES.

Figure 1 shows the age adjusted all cause mortality rates and proportion of mortality attributable to specific causes according to the level of SES. Compared with the men of higher SES, men of lower SES had higher mortality rate, not only from all cause but also from all kinds of specific causes categorised by the amenability to medical interventions. Mortality from external and avoidable causes accounted for the higher proportion of total mortality in lower SES group than in higher SES group. In

Table 2 Mortality from partly avoidable causes that occurred among 759665 men aged 30-64 during the five year follow up period (1992-1996), Korea

\begin{tabular}{|c|c|c|c|c|c|}
\hline ICD 8 code & ICD 9 code & ICD 10 code & Causes of death & $\begin{array}{l}\text { Number of } \\
\text { deaths }\end{array}$ & Type of intervention \\
\hline 070 & 070 & B15-B19 & Viral hepatitis & 20 & Prevention \\
\hline $153-154$ & $153-154$ & $\mathrm{C} 18-\mathrm{C} 20$ & $\begin{array}{l}\text { Malignant neoplasm of large intestine, rectum and rectosigmoid } \\
\text { junction }\end{array}$ & 273 & Treatment \\
\hline 204 & 204 & C91 & Lymphatic leukaemia & 9 & Treatment, controversial \\
\hline 250 & 250 & E10-E14 & Diabetes mellitus & 405 & Treatment \\
\hline 345 & 345 & G40 & Epilepsy, generalised convulsive & 10 & Treatment \\
\hline $400-404$ & $401-405$ & I10-I15 & Hypertensive disease & 229 & Treatment \\
\hline $410,411,413$ & $410,411,413$ & $\mathrm{I} 20, \mathrm{I} 21, \mathrm{I} 24$ & Hypertensive disease with vascular complications of heart & 547 & Prevention \\
\hline $430-438$ & $430-438$ & I60-I69 & Hypertensive disease with vascular complications of brain & 1247 & Prevention \\
\hline $531-533$ & $531-533$ & $\mathrm{~K} 25-\mathrm{K} 27$ & $\begin{array}{l}\text { Ulcer of stomach or duodenum with or without haemorrhage or } \\
\text { perforation }\end{array}$ & 25 & Treatment \\
\hline 746-747 & $746-747$ & Q20-Q28 & Congenital anomalies of heart and great vessels & 4 & Treatment \\
\hline
\end{tabular}


Table 3 Age adjusted baseline characteristics of 759665 men aged 30-64 according to the level of socioeconomic status, Korea

\begin{tabular}{|c|c|c|c|c|c|}
\hline \multirow[b]{2}{*}{ Variables } & \multirow[b]{2}{*}{ Subjects (n) } & \multicolumn{4}{|c|}{ Levels of socioeconomic status } \\
\hline & & Level I & Level II & Level III & Level IV \\
\hline Cholesterol $(\mathrm{mg} / \mathrm{dl})^{\star}$ & 705561 & 189.2 & 191.0 & 193.6 & 194.1 \\
\hline Systolic blood pressure $(\mathrm{mm} \mathrm{Hg})^{\star}$ & 705363 & 125.3 & 124.3 & 123.5 & 123.5 \\
\hline Diastolic blood pressure $(\mathrm{mm} \mathrm{Hg})^{\star}$ & 705559 & 81.4 & 81.1 & 80.9 & 80.8 \\
\hline Obesity $(\%) \dagger$ & 704746 & & & & \\
\hline Body mass index $<20 \mathrm{~kg} / \mathrm{m}^{2}$ & & 10.8 & 9.3 & 8.4 & 8.6 \\
\hline Body mass index $\geqslant 25 \mathrm{~kg} / \mathrm{m}^{2}$ & & 19.6 & 23.5 & 25.4 & 24.2 \\
\hline Smoking habit $(\%) \dagger$ & 705755 & & & & \\
\hline Current smoker & & 67.2 & 61.6 & 57.0 & 49.0 \\
\hline Former smoker & & 14.9 & 18.0 & 20.0 & 23.2 \\
\hline Alcohol drinking habit & 706129 & & & & \\
\hline Occasional drinker (\%) & & 52.6 & 52.5 & 52.5 & 52.5 \\
\hline Frequent drinker (\%) & & 21.9 & 22.2 & 22.3 & 22.0 \\
\hline Area of residency $(\%) \dagger$ & 759665 & & & & \\
\hline Large city & & 48.3 & 46.9 & 50.5 & 61.7 \\
\hline County & & 23.2 & 21.7 & 15.9 & 8.0 \\
\hline "High" group occupation (\%)† & 759530 & 3.9 & 17.1 & 32.6 & 67.4 \\
\hline
\end{tabular}

${ }^{\star}$ Analysis of covariance procedure: $\mathrm{p}<0.01$. $†$ Mantel-Haenszel $\chi^{2}$ procedure: $\mathrm{p}<0.01$.

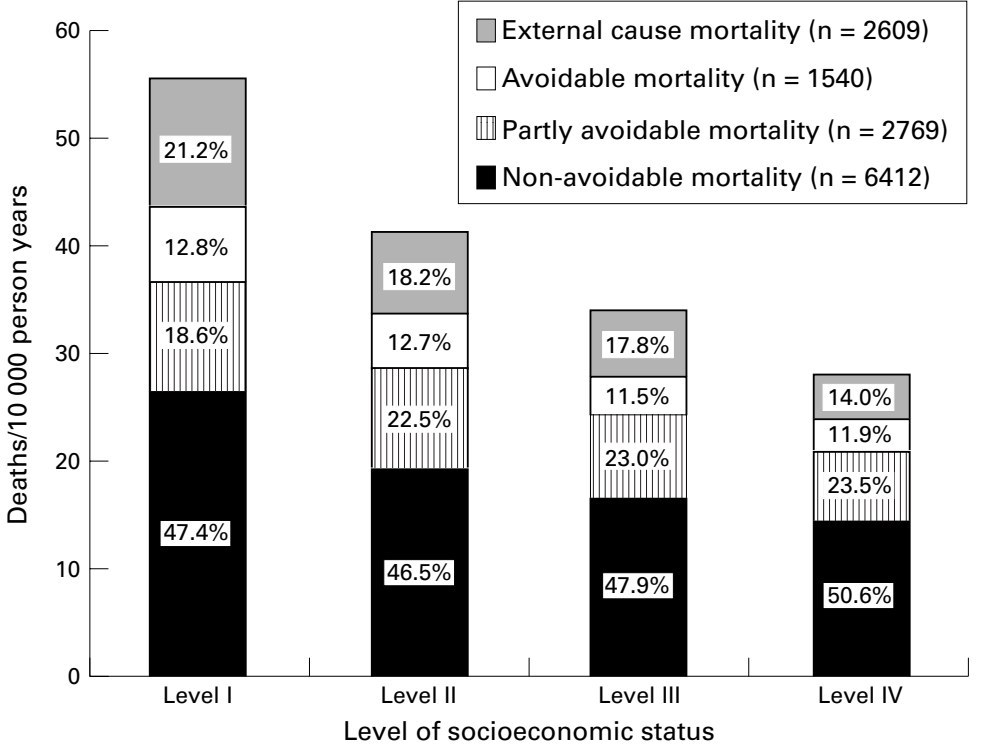

Figure 1 Age adjusted all cause mortality rate and proportion (\%) of mortality attributable to specific causes by the level of socioeconomic status in 759665 men aged 30-64, 1992-1996, Korea. Specific causes of death were categorised according to the amenability to medical intervention.

contrast, mortality from non-avoidable causes accounted for the higher proportion of total mortality in higher SES group than in lower SES group.

Results of the analyses applying the Cox proportional hazard model are presented in table 4. Risk of all cause mortality increased progressively with the decrease of the socioeconomic level. For each cause, the table shows the relation between mortality and SES with adjustment for various potential risk factors in the cumulative stage. As more factors were added to the multivariate analysis, the associations between SES and mortality were progressively attenuated but were persistent. Adjustment for other social factors such as occupation and area of residency reduced the gap in the risk of mortality across different levels of SES in various degrees. After further adjustment for biological and behavioural risk factors, the higher risk of mortality from most causes in men of lowest SES attenuated slightly but still remained significant.
KEY POINTS

- Significant inverse relation between socioeconomic status (SES) and mortality, previously reported from developed countries, was also observed in a population of less developed country.

- The gap in the risk of mortality between highest and lowest SES groups was in the order of external cause, avoidable, nonavoidable, and partly avoidable mortality.

- After controlling the known risk factors of mortality, significantly higher risks of mortality in lowest SES group were attenuated but persisted.

- Socioeconomic differentials in mortality seem to be influenced not only by the quality of health care and different distribution of risk factors but also by other aspects of SES.

While the risks of death from most causes increased in men of lower SES, there was considerable heterogeneity in the strength of these relations according to the specific causes. The strength of the association between the risk of mortality and SES was influenced by the various degrees of amenability to medical intervention in the causes of death. Compared with the men of highest SES, the men of lowest SES had significantly higher risk of avoidable mortality (relative risk $(\mathrm{RR})=1.65,95 \%$ confidence intervals: $1.38,1.98)$. The gap in the risk of avoidable mortality between highest and lowest SES groups was larger than that of the partly avoidable $(\mathrm{RR}=1.22 ; 1.06,1.40)$ and non-avoidable mortality $(\mathrm{RR}=1.54 ; 1.41$, 1.69). In case of cancer, the men of lowest SES had an adjusted $R R$ of $1.46(1.16,1.83)$ from avoidable cancer death, $1.25(1.11,1.40)$ from non-avoidable cancer, and a reduced RR of $0.48(0.29,0.78)$ from partly avoidable cancer death. Risk of mortality from external causes $(\mathrm{RR}=2.26 ; 1.94,2.64)$, considered to be influenced by extra-medical factors, was extremely high in lowest SES group even after controlling biological and social risk factors.

The adjusted RR of mortality from cerebrovascular disease, one of partly avoidable causes, was $1.67(1.35,2.06)$ in the lowest SES group. There was no significant relation between mortality from coronary heart disease and SES.

\section{Discussion}

Nearly twofold difference in the risk of age adjusted all cause mortality between the lowest SES group and the highest SES group was observed in Korean male civil servants. This socioeconomic differential in mortality, consistent with the results of other studies performed in well developed western countries, ${ }^{3-10}$ suggest that SES can influence mortality regardless of the developmental stage of the country.

For the purpose of exploring the causes of the differences in mortality according to SES, the effect of the quality of health care was examined through a comparison of the 
Table 4 Adjusted relative risks of mortality (95\% confidence limits) from all cause, avoidable causes, partly avoidable causes, non-avoidable causes, and external causes in 759665 men aged 30-64 by the level of socioeconomic status, 1992-1996, Korea

\begin{tabular}{|c|c|c|c|c|}
\hline \multirow[b]{2}{*}{ Causes of death (no of deaths) } & \multicolumn{4}{|c|}{ Level of socioeconomic status } \\
\hline & $\begin{array}{l}\text { Level I (lowest) } \\
(n=215 \text { 842) }\end{array}$ & Level II ( $n=177$ 098) & $\begin{array}{l}\text { Level III } \\
(n=196505)\end{array}$ & $\begin{array}{l}\text { Level IV (highest) } \\
(n=170220)\end{array}$ \\
\hline \multicolumn{5}{|l|}{ All causes $(n=13330)$} \\
\hline Age & $2.07^{\star \star}(1.97,2.17)$ & $1.49^{\star \star}(1.40,1.57)$ & $1.19^{\star \star}(1.13,1.25)$ & 1 \\
\hline Age, occupation, area of residency & $1.72^{\star \star}(1.63,1.82)$ & $1.25^{\star \star}(1.17,1.33)$ & $1.03(0.98,1.09)$ & 1 \\
\hline All factorst & $1.59^{\star \star}(1.50,1.69)$ & $1.18^{\star \star}(1.11,1.27)$ & $1.01(0.95,1.07)$ & 1 \\
\hline \multicolumn{5}{|l|}{ Avoidable causes $(n=1540)$} \\
\hline Age & $2.27^{\star \star}(1.99,2.59)$ & $1.60^{\star \star}(1.36,1.90)$ & $1.22^{\star \star}(1.06,1.40)$ & 1 \\
\hline Age, occupation, area of residency & $1.92^{\star \star}(1.63,2.26)$ & $1.36^{\star \star}(1.12,1.64)$ & $1.06(0.90,1.24)$ & 1 \\
\hline All factors $\dagger$ & $1.65^{\star \star}(1.38,1.98)$ & $1.27^{\star}(1.04,1.56)$ & $1.01(0.85,1.20)$ & 1 \\
\hline \multicolumn{5}{|l|}{ Partly avoidable causes $(n=2769)$} \\
\hline Age & $1.70^{\star \star}(1.53,1.88)$ & $1.53^{\star \star}(1.35,1.73)$ & $1.28^{\star \star}(1.16,1.42)$ & 1 \\
\hline Age, occupation, area of residency & $1.41^{\star \star}(1.25,1.60)$ & $1.28^{\star \star}(1.11,1.46)$ & $1.11(0.99,1.24)$ & 1 \\
\hline All factors $\dagger$ & $1.22^{\star \star}(1.06,1.40)$ & $1.13(0.97,1.32)$ & $1.05(0.93,1.19)$ & 1 \\
\hline \multicolumn{5}{|l|}{ Non-avoidable causes $(n=6412)$} \\
\hline Age & $1.96^{\star \star}(1.84,2.10)$ & $1.33^{\star \star}(1.22,1.44)$ & $1.13^{\star \star}(1.06,1.21)$ & 1 \\
\hline Age, occupation, area of residency & $1.64^{\star \star}(1.51,1.78)$ & $1.12^{\star}(1.02,1.23)$ & $0.99(0.91,1.07)$ & 1 \\
\hline All factors $\dagger$ & $1.54^{\star \star}(1.41,1.69)$ & $1.06(0.96,1.17)$ & $0.97(0.89,1.06)$ & 1 \\
\hline \multicolumn{5}{|l|}{ External causes $(n=2609)$} \\
\hline Age & $2.95^{\star \star}(2.61,3.32)$ & $2.02^{\star \star}(1.77,2.31)$ & $1.49^{\star \star}(1.32,1.69)$ & 1 \\
\hline Age, occupation, area of residency & $2.27^{\star \star}(1.96,2.62)$ & $1.61^{\star \star}(1.38,1.87)$ & $1.26^{\star \star}(1.10,1.44)$ & 1 \\
\hline All factors $\dagger$ & $2.26^{\star \star}(1.94,2.64)$ & $1.65^{\star \star}(1.41,1.93)$ & $1.29^{\star \star}(1.12,1.48)$ & 1 \\
\hline \multicolumn{5}{|l|}{ Cerebrovascular disease $(n=1247)$} \\
\hline Age & $2.11^{\star \star}(1.82,2.45)$ & $1.54^{\star \star}(1.28,1.85)$ & $1.39^{\star \star}(1.19,1.61)$ & 1 \\
\hline Age, occupation, area of residency & $1.96^{\star \star}(1.62,2.37)$ & $1.42^{\star \star}(1.15,1.77)$ & $1.31^{\star \star}(1.10,1.56)$ & 1 \\
\hline All factorst & $1.67^{\star \star}(1.35,2.06)$ & $1.22(0.97,1.55)$ & $1.20(0.99,1.45)$ & 1 \\
\hline \multicolumn{5}{|l|}{ Coronary heart disease $(n=577)$} \\
\hline Age & $1.22(0.96,1.55)$ & $1.52^{\star \star}(1.18,1.96)$ & $0.98(0.78,1.23)$ & 1 \\
\hline Age, occupation, area of residency & $1.06(0.80,1.41)$ & $1.33^{\star}(1.00,1.78)$ & $0.87(0.68,1.13)$ & 1 \\
\hline All factorst & $0.94(0.69,1.29)$ & $1.20(0.88,1.64)$ & $0.83(0.64,1.09)$ & 1 \\
\hline \multicolumn{5}{|l|}{ Cancer, avoidable $(\mathrm{n}=918)$} \\
\hline Age & $1.97^{\star \star}(1.66,2.34)$ & $1.41^{\star \star}(1.13,1.76)$ & $1.21^{\star}(1.01,1.44)$ & 1 \\
\hline Age, occupation, area of residency & $1.53^{\star \star}(1.25,1.89)$ & $1.11(0.87,1.42)$ & $0.98(0.80,1.20)$ & 1 \\
\hline All factors $\dagger$ & $1.46^{\star \star}(1.16,1.83)$ & $1.03(0.79,1.34)$ & $0.95(0.76,1.18)$ & 1 \\
\hline \multicolumn{5}{|l|}{ Cancer, partly avoidable $(n=282)$} \\
\hline Age & $0.79(0.54,1.16)$ & $1.20(0.82,1.75)$ & $1.20(0.88,1.62)$ & 1 \\
\hline Age, occupation, area of residency & $0.58^{\star}(0.38,0.89)$ & $0.91(0.60,1.38)$ & $0.95(0.67,1.32)$ & 1 \\
\hline All factorst & $0.48^{\star \star}(0.29,0.78)$ & $0.82(0.52,1.29)$ & $0.88(0.61,1.25)$ & 1 \\
\hline \multicolumn{5}{|l|}{ Cancer, non-avoidable $(\mathrm{n}=3754)$} \\
\hline Age & $1.53^{\star \star}(1.40,1.67)$ & $1.22^{\star \star}(1.09,1.35)$ & $1.13^{\star \star}(1.03,1.23)$ & 1 \\
\hline Age, occupation, area of residency & $1.28^{\star \star}(1.15,1.43)$ & $1.03(0.91,1.16)$ & $0.98(0.89,1.09)$ & 1 \\
\hline All factors $\dagger$ & $1.25^{\star \star}(1.11,1.40)$ & $0.99(0.87,1.13)$ & $0.97(0.88,1.08)$ & 1 \\
\hline
\end{tabular}

${ }^{\star} \mathrm{p}<0.05 ;{ }^{\star} \mathrm{p}<0.01$. †Adjusted for age, occupation, area of residence, cholesterol, systolic blood pressure, body mass index, smoking, drinking alcohol.

differences across SES groups between avoidable mortality and non-avoidable mortality. The authors assumed that, without any influence of health care delivery on the relation between SES and mortality, the mortality gap across SES groups would be very similar regardless of the medical amenability of the causes of death. Larger gap in the risk of avoidable mortality among different levels of SES than that of partly avoidable and non-avoidable mortality seems to support the possibility that variations in the quality of health care delivery contribute, in some part, to making the socioeconomic differentials in mortality. Although all the subjects were covered by health insurance, co-payment benefit structure where the patient pays for a certain portion of the medical expenditure might cause some hindrance to the use of medical care, especially for men of lower SES. Some previous studies reported that, even in populations with health insurance, the extent of the insurance coverage was related to the access and quality of preventive care, high technology procedures, and treatments. ${ }^{27-31}$

Considering the significant inverse relation between SES and mortality from nonavoidable causes observed in our study and other study, ${ }^{32}$ it is impossible to fully explain the influence of SES on mortality with only an inadequate access or poor quality of health care. There was also a report arguing that universal health insurance like the National Health Service is not the only remedy for health inequality among different SES groups. ${ }^{33}$ The association between avoidable mortality and socioeconomic factors was stronger than the association between avoidable mortality and health services in studies using the aggregate data, ${ }^{34}{ }^{35}$ which suggests the presence of other causes. Health care service might not be able to completely eliminate the deaths known to be preventable by the avoidance of exposure to smoking and other environmental health hazards.

Reduced risk of mortality from partly avoidable cancer is probably attributable to the fact that partly avoidable cancer consists mainly of colorectal cancer. In previous studies, the risk of colon cancer has been consistently associated with higher SES. ${ }^{36-38}$ Although mortality from colorectal cancer has been considered to be partly avoidable by medical intervention, adequate treatment alone cannot compensate for the higher incidence in the higher SES group. A gap in the incidence of the disease rather than a gap in the quality of health care among different SES groups seems to be more important in relation between colorectal cancer and SES. 
In this study, there was no relation between SES and mortality from coronary heart disease. However there have been many other studies that have reported that people of lower SES had higher risk of death from coronary heart disease. ${ }^{45}{ }^{39}$ The discrepancy between the results of this study and other studies might be explained by the variations in the developmental stages of the society in which the study subjects belonged and the variations in the risk factor distribution among the study subjects. The changes in the relation between SES and coronary heart disease from the beginning of 1900 s to the latter part of the 20th century have already been reported in the studies conducted in the United Kingdom and the United States. ${ }^{40}{ }^{41}$ According to the findings observed in those studies, the changing effect of social status seemed to be attributable partly to differential changes in certain risk factors of coronary heart disease, as intervening factors. The diverse distribution of the cardiovascular risk factors such as cholesterol, blood pressure, overweight, and smoking within the higher and lower SES groups might be the cause of the null relation between the mortality from coronary heart disease and SES. However, the reason for the absence of any significant association between the mortality from coronary heart disease and SES could not be clearly understood from this study alone.

Distribution of the risk factors among the SES groups observed in this study was very different from other studies. ${ }^{18}{ }^{1922-25}$ The same significant inverse relation between mortality and SES as observed in other studies, despite the differences in the risk factor distributions between the studies, ${ }^{6} 742$ does not favour the decisive role of the risk factors in making socioeconomic differentials in mortality. In addition, the persistence of the significant relation even after adjusting the risk factors, observed in several studies including ours, ${ }^{42-45}$ seems to suggest the presence of other significant factors or the possibility that SES is an independent risk factor of mortality. However, largest reduction in the risk of mortality from most causes after controlling the behavioural and biological risk factors in the lowest SES group compared with other groups confirmed the need for controlling such factors for the purpose of reducing the mortality gap among the SES groups.

The association between the occupational group and mortality has been observed in many studies. ${ }^{42} 4647$ Residence in a poverty striken area was also reported to be associated with increased risk of mortality. ${ }^{48}$ The attenuation of association between the SES and mortality after adjusting the occupation and the area of residency seemed to suggest these factors as important factors that contribute to the socioeconomic differentials in mortality. However, thorough examination of these factors was not possible in this study with the general information on the occupation and the area of residency.

In this study, the authors examined the relation between SES and mortality, considering the causes of mortality and various risk factors.
There were some limitations caused from measuring the SES by using the grade of monthly salary and restricting the range of study subjects to civil service personnel. Although homogeneity in the job category of study subjects made it possible to rule out the influences coming from the differences in health insurance coverage and employment status, the findings of this study cannot be generalised to those without health insurance and to those who are unemployed or self employed. The grade of monthly salary used as an indicator of SES despite the strong correlation with the employment grade, may not fully reflect the economic status of the individual person. In addition, avoidable disease classified by the Rutstein group might be out of date. If recent remarkable development in health care is fully considered, some causes of mortality that were classified as non-avoidable disease in this study may be classified as avoidable or partly avoidable diseases. Despite these limitations, our study results have some implications in the point of having documented that the significant inverse relation between SES and mortality can be observed not only in developed countries but also in the less developed countries. In this study the differences in mortality according to SES could not be fully explained by the variations in the risk factor distribution and the quality of health care. A large part of the mortality differentials remains unexplained. Further investigations focused on diverse aspects of health including not only the biological but also the social and environmental factors are needed.

Funding: this study was supported by the Korea Medical Insurance Corporation and the Samsung Medical Centre.

1 Wilkinson RD. National mortality rate: the impact of inequality? Am f Public Health 1992;82:1082-4.

Davey Smith G. Income inequality and mortality: why are they related? $B M F 1996 ; 312: 987-8$.

3 Näyhä S. Social group and mortality in Finland. $\mathrm{Br} \mathcal{F}$ Prev Soc Med 1977;31:231-7.

4 Salonen JT. Socioeconomic status and risk of cancer, Salonen JT. Socioeconomic status and risk of cancer,
cerebral stroke, and death due to coronary heart disease and any disease: a longitudinal study in eastern Finland. $\mathcal{f}$ Epidemiol Community Health 1982;36:294-7.

Epidemiol Community Health 1982;36:294-7.
5 Levi F, Negri E, La Vecchia C, Te VC. Socioeconomic groups and cancer risk at death in the Swiss Canton of Vaud. Int f Epidemiol 1988;17:711-17.

6 Davey Smith G, Shipley MJ, Rose G. Magnitude and causes of socioeconomic differentials in mortality: further evidence from the Whitehall study. $\mathcal{F}$ Epidemiol Community Health 1990;44:265-70.

7 Davey Smith G, Leon D, Shipley MJ, et al. Socioeconomic differentials in cancer among men. Int $\mathcal{F}$ Epidemiol 1991;20: 339-45.

8 Sorlie PD, Backlund E, Keller JB. US mortality by economic, demographic, and social characteristics: The National Longitudinal Mortality Study. Am f Public Health 1995;85:949-56.

9 Backlund E, Sorlie PD, Johnson NJ. The shape of the relationship between income and mortality in the United States: Evidence from the National Longitudinal Mortality Study. Ann Epidemiol 1996;6:12-20.

10 Wannamethee SG, Shaper AG. Socioeconomic status within social class and mortality: A prospective study in middle-aged British men. Int f Epidemiol 1997;26:532-41.

11 Newacheck PW. Access to ambulatory care for poor persons. Health Serv Res 1988;23:401-19.

12 Howell EM. Low-income persons' access to health care: NMCUES Medicaid data. Public Health Rep 1988;103: 507-14.

13 Poikolainen K, Eskola J. The effect of health services on mortality: Decline in death rates from amenable and nonamenable causes in Finland, 1969-81. Lancet 1986;i:199202 .

14 Rutstein DD, Berenberg W, Chalmers TC, et al. Measuring the quality of medical care: A clinical method. $N$ Engl $\mathcal{F}$ Med 1976;294:582-8. 
15 Charlton JRH, Hartley RM, Silver R, et al. Geographical variation in mortality from conditions amenable to medica 1983;i:691-6.

16 Charlton JRH, Velez R. Some international comparisons of mortality amenable to medical intervention. BMF 1986; 292:295-301

17 Poikolainen K, Eskola J. Health services resources and their relation to mortality from causes amenable to health care intervention: A cross-national study. Int $\mathcal{f}$ Epidemiol 1988;17:86-9.

18 Millar WJ, Wigle DT. Socioeconomic disparities in risk factors for cardiovascular disease. Can Med Assoc 7 1986;134: 127-32.

19 Jacobsen BK, Thelle DS. Risk factors for coronary heart disease and level of education: The Troms $\phi$ Heart Study. Am 7 Epidemiol 1988;127:923-32.

20 Greiser E, Joeckel KH, Giersiepen K, et al. Cardiovascular disease risk factors, CHD morbidity and mortality in the Federal Republic of Germany. Int f Epidemiol 1989;18: File-24.

21 Gold MR, Franks P. The social origin of cardiovascular risk: An investigation in a rural community. Int $\mathcal{f}$ Health Serv 1990;20:405-16.

22 Winkleby MA, Fortmann SP, Barrett DC. Social class disparities in risk factors for disease: Eight-year prevalence patterns by level of education. Prev Med 1990;19:1-12

23 Marmot MG, Davey Smith G, Stansfeld S, et al. Health inequalities among British civil servants: the Whitehall II study. Lancet 1991;337:1387-93.

24 Winkleby MA, Jatulis DE, Frank E, et al. Socioeconomic status and health: How education, income, and occupation contribute to risk factors for cardiovascular disease. $A m \mathcal{F}$ Public Health 1992; 82:816-20

25 Blane D, Hart CL, Davey Smith G, et al. Association of cardiovascular disease risk factors with socioeconomic position during childhood and during adulthood. $B M \mathcal{F}$ 1996;313:1434-8.

26 Allison PD. Survival analysis using the SAS system: A practical guide. Cary, NC: SAS Institute Inc, 1995:111-184.

27 cal guide. Cary, NC: SAS Institute Inc, 1995:111-184. interim results from a controlled trial of cost sharing in health insurance. N Engl f Med 1981;305:1501-7.

28 Woolhandler S, Himmelstein DU. Reverse targeting of preventive care due to lack of health insurance. $7 A M A$ 1988;259:2872-4

29 Weissman J, Epstein AM. Case mix and resource utilization by uninsured hospital patients in the Boston metropolitan area. FAMA 1989;261:3572-6.

30 Wenneker MB, Weissman JS, Epstein AM. The association of payer with utilization of cardiac procedures in Massachusetts. $7 A M A$ 1990;264:1255-60

31 Brook RH, Kamberg CJ, Lohr KN, et al. Quality of ambulatory care: epidemiology and comparison by insurance status and income. Med Care 1990;28:392-433.
32 Marmot MG, Kogevinas M, Elston MA. Social/economic status and disease. Ann Rev Public Health 1987;8:111-35.

33 Adler NE, Boyce WT, Chesney MA, et al. Socioeconomic inequalities in health: No easy solution. $\mathcal{F} A M A$ 1993;269: 3140-5.

34 Mackenbach JP, Kunst AE, Looman CWN, et al. Regional differences in mortality from conditions amenable to medical intervention in The Netherlands: a comparison of four time periods. F Epidemiol Community Health 1988;42:32532 .

35 Mackenbach JP, Bouvier-Colle MH, Jougla E. "Avoidable" mortality and health services: a review of aggregate data studies. F Epidemiol Community Health 1989;44:106-11.

36 Haenszel W, Correa P, Cuello C. Social class differences among patients with large-bowel cancer in Cali, Colombia. f Natl Cancer Inst 1975;54:1031-5.

37 Crowther JS, Drasar BS, Hill MJ, et al. Faecal steroids and bacteria and large bowel cancer in hong Kong by socio-economic groups. Br F Cancer 1976;34:191-8.

38 Vågerö D, Persson G. Occurrence of cancer in socioeconomic groups in Sweden. Scand F Soc Med 1986;14:15160

39 Pocock SJ, Shaper AG, Cook DG, et al. Social class differences in ischemic heart disease in British men. Lancet $1987 ; \mathbf{i}: 197-201$

40 Marmot MG, Adelstein AM, Robinson N, et al. Changing social-class distribution of heart disease. $\mathrm{Br}$ Med F 1978;ii: 1109-12.

41 Morgenstern $\mathrm{H}$. The changing association between social status and coronary heart disease in a rural population. Soc Sci Med 1980;14A:191-201.

42 Davey Smith G, Hart C, Blane D, et al. Lifetime socioeconomic position and mortality: Prospective obsevational study. BMҰ 1997;314:547-52.

43 Marmot MG, Shipley MJ, Rose G. Inequalities in death-specific explanations of a general pattern? Lancet 1984;i:1003-6.

44 Haan M, Kaplan GA, Camacho T. Poverty and health: Prospective evidence from the Alameda County Study. Am f Epidemiol 1987;125:989-98.

45 Davey Smith G, Neaton JD, Wentworth D, et al. Socioeconomic differentials in mortality risk among men screened for the Multiple Risk Factor Intervention Trial: I. White men. Am 7 Public Health 1996;86:486-96.

46 Koskenvuo M, Sarna S, Kaprio J, et al. Cause specific morality by marital status and social class in Finland during 1969-71. Soc Sci Med 1979;13A:691-7.

47 Lundberg O. Class and health: comparing Britain and Sweden. Soc Sci Med 1986;23:511-17.

48 Haan M, Kaplan GA, Camacho T. Poverty and health: prospective evidence from the Alameda County Study. $\mathrm{Am} \mathcal{F}$ Epidemiol 1987;125:989-98. 